\title{
Simulation of dissolved nutrient export from the Dongjiang river basin with a grid-based NEWS model
}

\author{
Qiangqiang Rong ${ }^{1,2}$, Meirong $\mathrm{Su}^{2}$, Zhifeng Yang ${ }^{2,3}$, Yanpeng Cai ${ }^{3}$, Wencong Yue ${ }^{1,2}$, Zhi Dang ${ }^{1, *}$ \\ ${ }^{1}$ School of Environment and Energy, South China University of Technology, 510006 Guangzhou, China \\ ${ }^{2}$ Research Center for Eco-environmental Engineering, Dongguan University of Technology, 523808 Dongguan, China \\ ${ }^{3}$ State Key Laboratory of Water Environment Simulation, School of Environment, Beijing Normal University, 100875 Beijing, China
}

\begin{abstract}
In this research, a grid-based NEWS model was proposed through coupling the geographic information system (GIS) with the Global NEWS model framework. The model was then applied to the Dongjiang River basin to simulate the dissolved nutrient export from this area. The model results showed that the total amounts of the dissolved nitrogen and phosphorus exported from the Dongjiang River basin were approximately 27154.87 and 1389.33 t, respectively. $90 \%$ of the two loads were inorganic forms (i.e. dissolved inorganic nitrogen and phosphorus, DIN and DIP). Also, the nutrient export loads did not evenly distributed in the basin. The main stream watershed of the Dongjiang River basin has the largest DIN and DIP export loads, while the largest dissolved organic nitrogen and phosphorus (DON and DOP) loads were observed in the middle and upper stream watersheds of the basin, respectively. As for the nutrient exported from each subbasin, different sources had different influences on the output of each nutrient form. For the DIN load in each subbasin, fertilization application, atmospheric deposition and biological fixation were the three main contributors, while eluviation was the most important source for DON. In terms of DIP load, fertilizer application and breeding wastewater were the main contributors, while eluviation and fertilizer application were the two main sources for DOP.
\end{abstract}

\section{Introduction}

Nutrient elements, such as nitrogen $(\mathrm{N})$ and phosphorus $(\mathrm{P})$, are the most important material basis for the development of aquatic ecosystem. The nutrient element contents of water body have great influence on the balance of aquatic ecosystem [1]. However, in recent years, under the combined impact of global change and human activities, nutrient element ratios of various aquatic ecosystems, especially the estuary ecosystem, has undergone great fluctuations [2]. Significant changes have taken place in estuarine nutrient cycle and flux in recent years [3]. Consequently, $\mathrm{N}$ and $\mathrm{P}$ contents of estuarine ecosystem loss the original balance, leading to eutrophication in estuary and coastal areas, which can further cause a series of ecological environment effects, such as harmful algal blooms, water hypoxia and acidification [4]. Thus, to prevent the ecological and environmental quality of estuarine area, it is very important to propose an effective method for nutrient export simulation in typical river estuary areas. Analyzing the $\mathrm{N}$ and $\mathrm{P}$ output from watershed to river estuary can provide a solid basis for aquatic environment regulation and water ecology protection. It will also satisfy the urgent requirement of watershed management and sustainable development.

In recent years, a number of scholars have carried out some research on the nutrient export model to analyze the nutrient output loads from various watersheds globally. Particularly, Global Nutrient Export from Watersheds Model, through integrating the migrating and transforming processes of multiple elements and forms, and establishing a unified simulation framework, has become an important tool for nutrient export simulation. For example, Mayorga et al. [5] proposed a Global NEWS model and provided a detailed model description. The model could be used as an effective tool to examine the impact of polices to reduce coastal eutrophication at regional to global scales. Strokal and Kroeze [6] used Global NEWS model and analyzed the past and future trends in river export of $\mathrm{N}$ and $\mathrm{P}$ to the coastal water of the Black Sea and assessed the associated potential for coastal eutrophication. At the same time, some researchers used Global NEWS Model to analyze the influence of social economy, farmland management and biogeophysical factors on the output of $\mathrm{N}$ and P. For instance, Yan et al. [7] estimated the inputs of nitrogen and exports of dissolved inorganic nitrogen from the Changiiang River to the estuary over the period 1970 2003. The result indicated that anthropogenically enhanced $\mathrm{N}$ inputs dominated river DIN yields under changing human pressures in the basin. Based on the Global NEWS model, Strokal et al. [8] developed a sub-basin model for the Pearl River basin over the period of 1970-2050 to analyze the trends in dissolved inorganic $\mathrm{N}$ and $\mathrm{P}$ and to identify the main sources of 
these nutrients and their locations. The results indicated that nutrient management in agriculture and sewage in down-stream areas was more effective in reducing coastal eutrophication than nutrient management in upand middle-stream areas of the Pearl River basin. Thus, the Global NEWS model is an effective tool for nutrient export simulation on global and regional scales. However, most of the input data for NEWS model are spatially distributed at $0.5^{\circ}$ resolutions (i.e. approximately 2890 $\mathrm{km}^{2}$ ). The data source with such a low resolution would reduce the spatial difference to a certain extent. Concurrently, the $\mathrm{N}$ and $\mathrm{P}$ output is highly dependent on terrain and soil conditions within a watershed, especially when the watershed consists of a large area with heterogeneous terrain and soil types [9]. Thus, it is very difficult for the Global NEWS model to analyze the spatial distribution of $\mathrm{N}$ and $\mathrm{P}$, when modeling the nutrient export on a watershed scale.

In this research, the Dongjiang River basin will be selected as the study area. Considering the nonuniformity of the underlying surface, a grid-based NEWS model will be first proposed, which improves the NEWS model through coupling the geographic information system (GIS) with the NEWS model framework. Then, the natural and social economic data of the Dongjiang River basin will be collected to establish the spatial and attribute database of the study area. Finally, the improved model will be applied to simulate the nutrient export in the Dongjiang River basin. Also, the spatial distribution will be analyzed to help provide a data basis for the NPS pollution management in the river estuary area. Thus, it is of great significance in both science and practice.

\section{Materials and methods}

\subsection{Development of the grid-based NEWS model}

NEWS model was developed to predict steady-state annual exports at the mouth of rivers for dissolved organic and inorganic nitrogen (DON and DIN); dissolved organic and inorganic phosphorus (DOP and DIP); and dissolved organic forms (DOC). It is a unified formulation of dissolved element-form sub-models [5].The export of each dissolved element form from watershed to river estuary can be calculated through the following equation:

$$
\mathrm{Yld}_{\mathrm{F}}=\mathrm{FE}_{\mathrm{riv}, \mathrm{F}} \cdot\left(\mathrm{RSpnt}_{\mathrm{F}}+\mathrm{RSdif}_{\mathrm{F}}\right)
$$

where the subscript $F$ means the nutrient form (i.e. DIN,

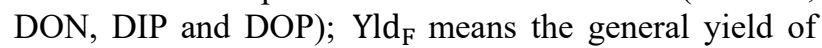
each dissolved element form; $\mathrm{RSpnt}_{\mathrm{F}}$ means $\mathrm{F}$ export through point sources $\left(\mathrm{kg} \cdot \mathrm{km}^{-2} \cdot \mathrm{yr}^{-1}\right)$; RSdif $\mathrm{F}$ means $\mathrm{F}$ export through diffuse sources $\left(\mathrm{kg} \cdot \mathrm{km}^{-2} \cdot \mathrm{yr}^{-1}\right) ; \mathrm{FE}_{\mathrm{riv}, \mathrm{F}}$ is a fraction $(0 \sim 1)$ of nutrient form $\mathrm{F}$ inputs to rivers that is exported at the basin mouth, corresponding to retention within the river system $\left(1-\mathrm{FE}_{\mathrm{riv}, \mathrm{F}}\right)$.

Point and diffuse sources represent the human waste emission and watershed sources and sinks, respectively. The two sources can be described as follows:

$$
\mathrm{RSpnt}_{\mathrm{F}}=\mathrm{FE}_{\mathrm{pnt}, \mathrm{F}} \cdot \mathrm{RSpnt}_{\mathrm{E}}
$$

$$
\begin{aligned}
& =\mathrm{FE}_{\mathrm{pnt}, \mathrm{F}} \cdot\left(1-\mathrm{hw}_{\text {frem, } \mathrm{E}}\right) \cdot I \cdot \mathrm{WShw}_{\mathrm{E}} \\
& \operatorname{RSdif}_{\mathrm{F}}=\left(\operatorname{RSdif}_{\mathrm{ant}_{\mathrm{F}}}+\mathrm{RSdif}_{\text {nat,F}}\right) \\
& =\left\{\left[\mathrm{FE}_{\mathrm{ws}, \mathrm{F}} \bullet \mathrm{WSdif}_{\mathrm{ant}, \mathrm{E}}+\mathrm{Ag}_{\mathrm{fr}} \bullet \mathrm{RSdif}_{\mathrm{ec}, \mathrm{F}}\right]\right. \\
& +\left[\mathrm{FE}_{\mathrm{ws}, \mathrm{nat}, \mathrm{F}} \bullet \mathrm{WSdif} \mathrm{nat}, \mathrm{E}\right. \\
& \left.\left.+\left(1-\mathrm{Ag}_{\mathrm{fr}}\right) \cdot \mathrm{RSdif}_{\mathrm{ec}, \mathrm{F}}\right]\right\}
\end{aligned}
$$

where WShw $_{\mathrm{E}} \quad\left(\mathrm{kg} \cdot \mathrm{km}^{-2} \cdot \mathrm{yr}^{-1}\right)$ represents a gross human-waste source to the watershed, $\mathrm{WShw}_{\mathrm{N}}=$ $\mathrm{WShwExc}_{\mathrm{N}}$ and $\mathrm{WShw}_{\mathrm{P}}=\mathrm{WShwExc}_{\mathrm{P}}+\mathrm{WShwDet}_{\mathrm{P}}$; $I$ is the fraction of the population connected to a sewage system; and $\mathrm{hw}_{\text {frem, }} \mathrm{E}$ is the fraction of $\mathrm{E}$ in sewage influent removed via wastewater treatment. $\mathrm{FE}_{\mathrm{pnt}, \mathrm{F}}$ is the fraction of $\mathrm{RSpnt}_{\mathrm{E}}$ emitted as form $\mathrm{F}$. $\mathrm{FE}_{\mathrm{pnt}, \mathrm{F}}$ for DIN is a linear, empirical function of $\mathrm{hw}_{\text {frem, } \mathrm{N}}$, while for all other $\mathrm{N}$ and $\mathrm{P}$ forms it is equal to a calibrated or default constant, $c_{\mathrm{F}}$. RSdif ${ }_{\mathrm{ant}, \mathrm{F}}$ and RSdif ${ }_{\text {nat,F }}$ mean the anthropogenic and natural inputs to watersheds, respectively, which include the net effect of land-based retention or removal (watershed sinks) of nutrients; $\mathrm{FE}_{\mathrm{ws}, \mathrm{F}}$ is a function of mean annual water runoff from land to streams $\left(\mathrm{R}_{\text {nat }}\right): \mathrm{FE}_{\mathrm{ws}, \mathrm{F}}=\mathrm{e}_{\mathrm{F}} \cdot f_{\mathrm{F}}\left(\mathrm{R}_{\text {nat }}\right)$;

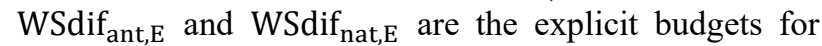
$\mathrm{N}$ and $\mathrm{P}$ on agricultural (anthropogenic, ant) and natural areas of the watershed; $R S$ dif $_{\mathrm{ec}, \mathrm{F}}$ represents direct diffuse inputs to rivers; $\mathrm{Ag}_{\mathrm{fr}}$ is the fraction of the basin covered by agricultural areas, and $\mathrm{FE}_{\mathrm{ws}, \mathrm{nat}, \mathrm{F}}=\mathrm{FE}_{\mathrm{ws}, \mathrm{F}}$ except for DIN. Thus, the total load $\left(\mathrm{Ld}_{\mathrm{F}}, \mathrm{Mg} \mathrm{yr}^{-1}\right)$ of each form $\mathrm{F}$ exported to river mouth can be calculated as: $\mathrm{Ld}_{\mathrm{F}}=\mathrm{Yld}_{\mathrm{F}} \cdot \mathrm{A}[5]$.

When the model was used on a watershed scale, data with higher resolution should be inputted to improve the accuracy and rationality of the simulation results. To achieve this goal, a grid-based NEWS model is proposed in this research based on GIS. Through this method, the watershed can be divided into numerous grids. The size of each grid can be determined based on the area of the basin and the requirement of output accuracy. Through the GIS platform, the data related to population density, land use, livestock and poultry breeding, social economy, topography condition can be transformed into grid format. Then, all the input data for NEWS model can be obtained and a grid-based nutrient export simulation can be carried out on a watershed scale.

\subsection{Research area and the data sources}

The Dongjiang River basin is located in south China (N22 $45^{\prime} \sim 25^{\circ} 20^{\prime}, 113^{\circ} 30^{\prime} \sim 116^{\circ} 45^{\prime}$ ). Providing more than 40,000,000 people of Guangdong Province and Hong Kong, it is the third longest tributary of the Pearl River basin. This river is located in a subtropical monsoon climate area, with an annual average temperature of $20.4{ }^{\circ} \mathrm{C}$. The precipitation is unevenly distributed during the year. The annual precipitation amount is $1500 \sim 2400 \mathrm{~mm}$. The terrain of the Dongjiang River basin is very complex. Mountain, hills and plain approximately account for $34.77 \%, 38.58 \%$ and $13.01 \%$ of the total area, respectively (Figure 1). Forestland, grassland, farmland, garden land, urban land and water 
area are the main land use types in this area [10].

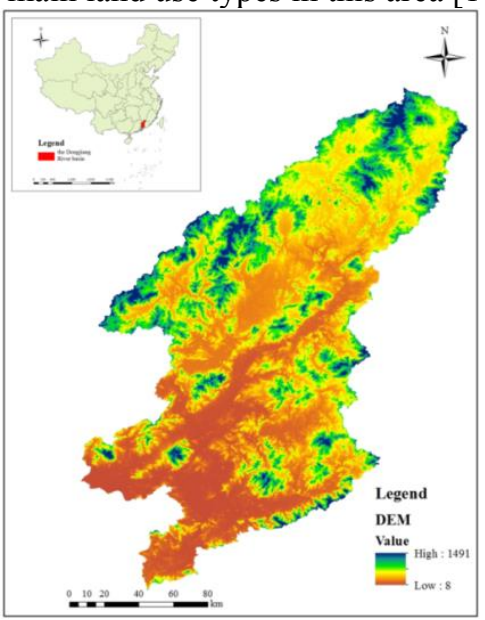

Figure 1 The location and DEM information of the Dongjiang River basin

In this research, the DEM was obtained from the Geospatial Data Cloud, with a resolution of $30 \mathrm{~m} \times 30 \mathrm{~m}$ (http://www.gscloud.cn/). Based on the DEM, the subcatchment of the basin can be generated. The population data is from the National Earth System Science Data Sharing Infrastructure (http://www.geodata.cn/index.html), with a resolution of $1 \mathrm{~km} \times 1 \mathrm{~km}$. The landuse data was obtained from GlobalCover $2009 \quad$ landuse map (http://due.esrin.esa.int/page_globcover.php), with a resolution of $300 \mathrm{~m} \times 300 \mathrm{~m}$. The agricultural information, including application amount of fertilizer, amount of livestock and poultry farming, crop area and yield, was obtained from County-level statistical yearbooks. All the input data was transformed in to raster format through GIS platform.

\section{Results and Discussion}

\subsection{Overall description of the nutrient export loads in the Dongjiang River basin}

The total amounts of the dissolved $\mathrm{N}$ and $\mathrm{P}$ exported from the Dongjiang River basin were approximately 27154.87 and 1389.33 t, respectively. Among these two loads, the inorganic $\mathrm{N}$ and $\mathrm{P}$ were the main forms, accounting for more than $90 \%$ of the total loads. Specifically, the exported amounts of DIN and DON were 26206.29 and $948.58 \mathrm{t}$, respectively. Those of DIP and DOP were 1328.21 and $61.12 \mathrm{t}$, respectively. There are many sources that can lead to the nutrient export from a watershed. Different sources may have different influences on the output of each nutrient form. In terms of DIN load from the research area, fertilizer application, atmospheric deposition and biological fixation were the three main contributors. The DIN amounts exported from these three sources were 13611.12, 5514.62 and 3194.16 $\mathrm{t}$, respectively. As for DON, the eluviation was the main contributor, accounting for more than $75 \%$ of the total load. With regard to DIP, fertilizer application, breeding wastewater and domestic wastewater were the three largest contributors. The DIP amounts exported from these three sources were 580.24, 352.65 and $233.08 \mathrm{t}$, respectively. As for DOP, the influence of eluviation and fertilizer application to the DOP export amounts was much more significant than the other sources. These two sources contributed more than $90 \%$ of the DOP load (Figure 2).

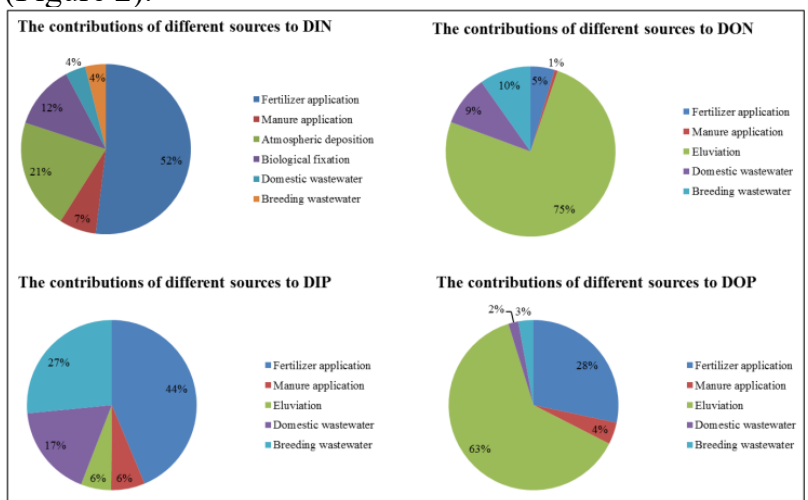

Figure 2 Contributions of different sources to the dissolved $\mathrm{N}$ and $\mathrm{P}$ in the Dongjiang River basin

\subsection{The distribution characteristics of nutrient export in the Dongjiang River basin}

The nutrient export loads did not evenly distributed in the area. Specifically, DIN and DIP export loads were largest in the main stream watershed of the Dongjiang River basin. Concurrently, the largest DON load was observed in the middle stream watershed of the basin (including Lijiang, Xinfeng and Qiuxiang River watersheds), while the largest DOP load was from the upper stream watershed of the basin (including Beiling and Xunwu River watersheds). The four largest loads from these four areas accounted for approximately $30 \%$ of the nutrient loads exported from the entire basin. Although the middle stream watershed of the Dongjiang River basin has the largest area (i.e. $10035.46 \mathrm{~km}^{2}$ ), all the nutrient export loads from this area were not the highest. On the contrary, with the smallest area (i.e. $4606.46 \mathrm{~km}^{2}$ ), the upper stream watershed of the basin had a relatively higher dissolved P loads. The smallest loads of DIN, DIP were observed in the upper and middle stream watersheds of the basin respectively, while those of DON and DOP were from the downstream watershed (Figure 3).

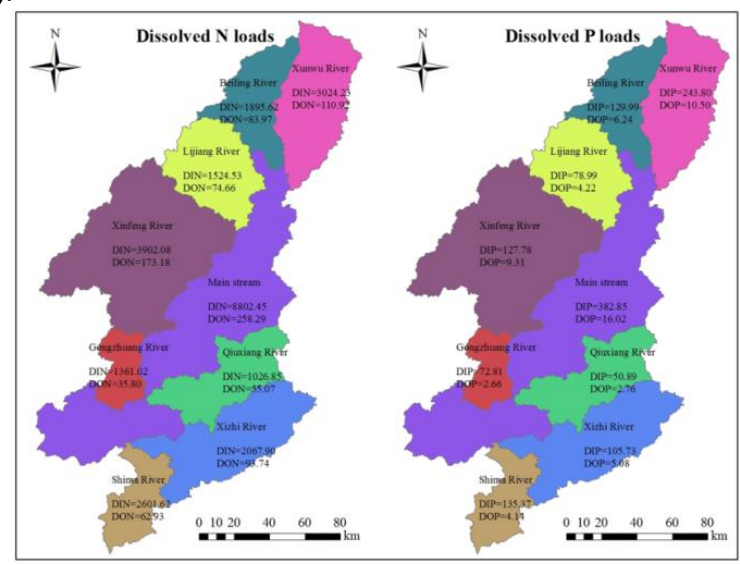

Figure 3 The distribution characteristics of nutrient export in the Dongjiang River basin 


\subsection{The contributions of different sources to the nutrient export in each subbasin}

As for the DIN load exported from each subbasin, fertilization application was the biggest contributor. More than $40 \%$ of the DIN load of each subbasin was from fertilization application. Besides, atmospheric deposition and biological fixation also had a significant influence on the DIN output. In terms of DON, eluviation was the most important source. More than $70 \%$ of the DON loads from most of the subbasins were contributed by eluviation. However, for dissolved P loads, the influences of different sources varied significantly in different subbasins. Specifically, in the Xunwu, Beiling, Gongzhuang, Shima and the main stream watersheds, fertilizer application was the biggest contributor to the DIP export. However, breeding wastewater was the biggest source for the DIP exported from Lijiang, Xinfeng, Qiuxiang and Xizhi River watersheds. With regard to DOP, eluviation and fertilizer application were the two biggest sources, accounting for almost $90 \%$ of the total DOP load in each subbasin (Figure 4).

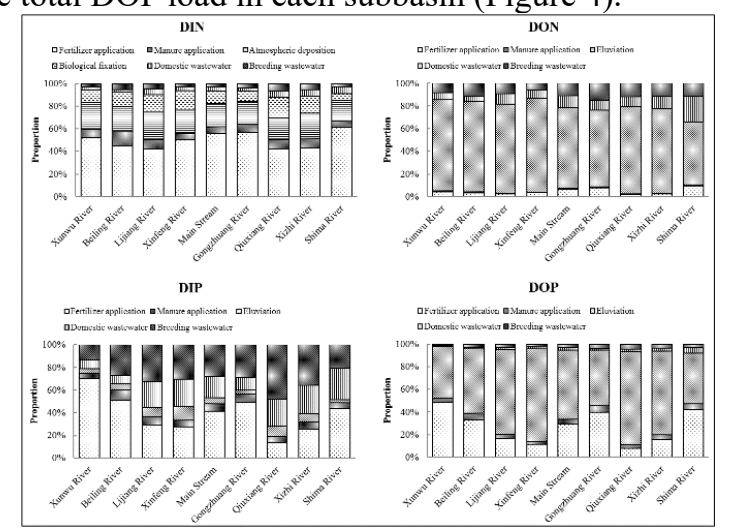

Figure 4 Contributions of different sources to the nutrient export in each subbasin

\section{Conclusions}

Under the influence of global change and human activities, plenty of nutrients have been discharged into the estuary area, leading to eutrophication in coastal areas. The ecological and environmental quality of estuarine area has obviously deteriorated. Thus, it is of great significance to propose an effective method for nutrient export simulation in typical river estuary areas. In this research, a grid-based NEWS model was proposed to simulate the nutrient export from the Dongiiang River basin. The results indicated that the total amounts of the dissolved N and P exported from the Dongjiang River basin were approximately 27154.87 and 1389.33 t, respectively. Among these two loads, the inorganic $\mathrm{N}$ and $\mathrm{P}$ were the main forms, accounting for more than $90 \%$ of the total loads. The nutrient export loads did not evenly distributed in the area. DIN and DIP export loads were largest in the main stream watershed of the Dongjiang River basin. Concurrently, the largest DON and DOP loads were observed in the middle and upper stream watersheds of the basin, respectively. At the same time, the smallest loads of DIN, DIP were observed in the upper and middle stream watersheds of the basin respectively, while those of DON and DOP were from the downstream watershed. As for the contributions of different sources to the dissolved nutrient export, fertilization application, atmospheric deposition and biological fixation were the three main contributors for the DIN load in each subbasin, while eluviation was the most important source for DON. In terms of DIP load, fertilizer application and breeding wastewater were the main contributors for each subbasin, while for DOP, eluviation and fertilizer application were the main sources.

\section{Acknowledgements}

This work was financially supported by the National Key R \& D Program of China (No.2017YFC0405900 and 2016YFC0502800), the Natural Science Foundation for Distinguished Young Scholars of Guangdong Province (No.2017A030306032), Guangdong Innovation Team Project for Colleges and Universities (No. 2016KCXTD023)， GDUPS (2017), the Scientific Research Foundation for High-level Talents and Innovation Team in Dongguan University of Technology (No. KCYKYQD2016001), and the Research Start-up Funds of DGUT (No. GC300501-16).

\section{References}

1. D.L. Stoliker, D.A. Repert, R.L. Smith, B. Song, D.R. Leblanc, T.D. Mccobb, C.H. Conaway, S.P. Hyun, D.C. Koh, H.S. Moon, Environ. Sci. Technol., 50(7), 3649 (2016).

2. N. Peyman, S.B. Tavakoly Sany, M. Tajfard, R. Hashim, M. Rezayi, D.J. Karlen, Environ. Sci. Proc. Impacts, 19(8), 1086 (2017).

3. Q.Q. Rong, J.T. Liu, Y.P. Cai, Z.H. Lu, Z.Z. Zhao, W.C. Yue, J.B. Xia, Ecol. Eng., 76, 57-65 (2015).

4. H.Wang, M. Dai, J. Liu, S.J. Kao, Z. Chao, W.J. Cai, G. Wang, Q. Wei, M. Zhao, Z. Sun, Environ. Sci. Technol., 50(5), 2255 (2016).

5. E. Mayorga, S.P. Seitzinger, J.A. Harrison, E. Dumont, A.H.W. Beusen, A.F. Bouwman, B.M. Fekete, C. Kroeze, G.V. Drecht, Environ. Modell. Softw., 25(7), 837-853 (2010).

6. M. Strokal and C. Kroeze, Reg. Environ. Change, 13(1), 179-192 (2013).

7. W.J.Yan, E. Mayorga, X.Y. Li, S.P. Seitzinger, A.F. Bouwman, Global Biogeochem. Cy., 24(4) (2010).

8. M.Strokal, C. Kroeze, L. Li, S. Luan, H. Wang, S. Yang, Y. Zhang, Biogeochemistry, 125(2), 221-242 (2015).

9. X.W. Ding, Z.Y. Shen, H. Qian, Z.F. Yang, W. Xing, R.M. Liu, J. Hydro., 383(3-4), 233-244 (2010).

10. Q.Q. Rong, M.R. Su, Z.F. Yang, Y.P. Cai, W.C. Yue, Z. Dang. 3rd International Conference on Advances in Energy Resources and Environment Engineering. (2018). 